\title{
Choques Externos e Desequilíbrios Financeiros: uma Interpretação sobre a Crise Brasileira
}

\author{
External Shocks and Financial Imbalances: \\ an Interpretation of the Brazilian Crisis
}

\author{
Martin Branco Kirsten* \\ Henrique Morrone ${ }^{\dagger}$
}

\begin{abstract}
Resumo
O presente artigo investiga as causas da recessão brasileira iniciada em 2014. Se por um lado o diagnóstico convencional atribui a crise a um descontrole das finanças públicas, por outro, diferentes interpretações enfatizam choques externos e um excessivo endividamento do setor privado. A hipótese alternativa é a de que a deterioração das contas públicas é uma consequência da crise e não a sua causa. Utiliza-se a metodologia desenvolvida por Toda e Yamamoto (1995), a fim de se verificar a hipótese de não causalidade de Granger entre as séries temporais dos resultados do setor privado, setor público e saldo em conta corrente do Banco Central do Brasil (BCB, 2017) para o período de novembro de 2002 a junho de 2017. Os resultados sugerem que os saldos dos setores externo e privado causam no sentido de Granger o saldo (resultado) do setor público.
\end{abstract}

Palavras-chave: Teorias da crise; Setores institucionais; Modelo econométrico; Brasil.

\begin{abstract}
This paper investigates the causes of the Brazilian recession that began in 2014. If, on the one hand, the conventional diagnosis attributes the crisis to a lack of control of public finances, other interpretations emphasize external shocks and excessive indebtedness of the private sector. The alternative hypothesis is that the deterioration of public accounts is a consequence of the crisis and not its cause. The methodology developed by Toda and Yamamoto (1995) is used to verify the hypothesis of non-causality of Granger between the time series of the balances of the private sector, public sector and current account, from the Central Bank of Brazil (BCB, 2017) for the 2002-2017 period. The results suggest that the balances of the external and private sectors cause in the Granger sense the balance (result) of the public sector.
\end{abstract}

Keywords: Crisis theories; Institutional sectors; Econometric model; Brazil.

JEL Classification: E00; E10; E12

Mestre em Economia do Desenvolvimento UFRGS.

† Professor Adjunto da UFRGS e do PPGE-UFRGS. E-mail: henrique.morrone@ufrgs.br 


\section{Introdução}

A economia brasileira passou por uma das crises mais graves de sua história. A economia, que apresentou uma taxa de crescimento média anual do PIB de 4,5\% entre 2006 e 2010 e de 2,3\% entre 2011 e 2014, passou por uma contração profunda em 2015 e 2016. Nesse último período, a economia nacional exibiu uma taxa média de crescimento negativa de $-3,5 \%$ (Carvalho, 2018). A desaceleração da economia brasileira, iniciada em 2011, e seu aprofundamento em uma recessão nos anos de 2015 e 2016 vêm sendo debatidos no meio acadêmico, principalmente após as eleições de 2014. Uma das interpretações da crise é a de que, a partir do segundo governo Lula (2007-2010) e com uma intensificação desse processo no primeiro governo de Dilma (2011-2014), o país teria adotado políticas intervencionistas, causando ineficiências microeconômicas, aumento da inflação e descontrole das contas públicas. Tal diagnóstico foi, em parte, reconhecido pelo próprio governo Dilma, ao nomear, na época de sua reeleição, o diretor-superintendente do banco Bradesco, Joaquim Levy, para a pasta da Fazenda.

Ainda que tal interpretação seja a mais utilizada, há teorias alternativas que podem ser mais adequadas para explicar a recessão nacional (Ocampo et al., 2009). A análise dos resultados dos saldos dos setores privado, público e externo pode contribuir para uma melhor compreensão das turbulências do período recente. Nota-se que, a partir da crise do subprime (2008/2009), houve a reversão de alguns indicadores. Em meados de 2008 houve o aumento dos déficits externos e superávits privados. A partir de 2012/2013 ocorreu uma crescente intensificação dos déficits públicos e superávits privados. Nesse contexto, o presente artigo tem como objetivo investigar as principais causas da crise brasileira e seus desdobramentos. A hipótese do trabalho é que a deterioração das contas públicas é um sintoma da recessão, não sua causa. Especificamente, almeja-se encontrar as principais relações de causa-efeito entre os setores institucionais (privado, público e externo) da economia. Para isso, examinaram-se as séries temporais dos resultados dos setores privado e público e o saldo em conta corrente do Banco Central do Brasil (BCB, 2017) no período de novembro de 2002 a junho de 2017. O procedimento de Toda e Yamamoto (1995) foi empregado a fim de averiguar a causalidade "no sentido de Granger" entre os saldos dos setores institucionais.

O presente estudo inova ao empregar uma metodologia alternativa para estimar a complexa relação entre os saldos dos setores da economia brasileira, servindo como um importante guia aos formuladores de política econômica. $\bigcirc$ diagnóstico correto da crise torna-se um elemento central para o design de políticas 
econômicas adequadas para a retomada do crescimento da economia nacional. Os resultados do procedimento indicaram que o saldo do setor privado causa no sentido de Granger os movimentos do setor público, e que o saldo do setor externo causa no sentido de Granger os movimentos do setor público. Para todas as demais hipóteses testadas, houve rejeição estatística. Os resultados verificados vão ao encontro das abordagens de Bresser-Pereira (2017) e de Borges (2016), que apontam a queda dos termos de troca como a principal causa da recessão em termos conjunturais. A análise de Rezende (2016, 2017), que aborda a insustentabilidade das posições financeiras do setor privado, respalda o resultado encontrado no presente estudo de que este último seria a causa da deterioração das contas públicas. Dessa forma o quadro fiscal brasileiro estaria sujeito a variáveis que não estão diretamente sob o controle do governo, e, por consequência, o diagnóstico liberal estaria propondo um remédio equivocado para a crise. Por meio de uma perspectiva distinta, os resultados empíricos contestam a hipótese teórica liberal de que os desequilíbrios fiscais causaram a recessão econômica brasileira. Decorre dos resultados encontrados que a origem da crise brasileira está associada aos movimentos (desequilíbrios) do setor privado e do setor externo.

Este artigo está organizado em quatro partes além desta introdução: a primeira parte apresenta as teorias convencionais e alternativas da crise brasileira; a segunda parte introduz o modelo de balanços setoriais de Cripps e Godley (1976), que expõe uma abordagem contábil dos três setores institucionais; a terceira parte descreve o procedimento de Toda e Yamamoto (1995); a última parte apresenta as conclusões.

\section{Do boom à recessão: as interpretações da crise brasileira}

Economistas liberais, em geral, atribuem a crise ao descontrole das contas públicas, o que teria gerado uma quebra na confiança dos agentes privados, forçando um aumento das taxas de juros e, decorrente disso, uma queda no investimento (Almeida et al., 2015) ${ }^{1}$. Desde a reeleição de Dilma Rousseff em outubro de 2014, a maioria das proposições de combate à recessão passou por esse

\footnotetext{
${ }^{1}$ Nesse diagnóstico, o conceito de dominância fiscal torna-se central. Entende-se por dominância fiscal uma situação em que o governo tem dificuldades para aumentar os juros a fim de combater a inflação. Se aumentar os juros, haverá temor quanto ao possível calote da dívida (que é uma função dos juros) e uma fuga de capitais. Isso, em última análise, provocará depreciação cambial e inflação. Logo, a situação fiscal condiciona os resultados e amarra a política monetária. Nesse sentido, um controle das contas públicas seria vital para um melhor desempenho econômico.
} 
diagnóstico. A solução para a crise consistiria na aplicação de um ajuste fiscal que retomasse a confiança dos agentes privados (Almeida et al. 2015; Pessoa, 2016).

Ainda que Almeida et al. (2015) e Pessoa (2016) deem ênfase ao período recente e principalmente coloquem a Nova Matriz Econômica (NME) como causadora da crise, em suas abordagens são postas questões mais estruturais e profundas que dizem respeito à Constituição Federal de 1988:

[...] a crise fiscal não decorre apenas do descontrole das contas públicas nos últimos anos. Não se trata de um desequilíbrio de curto prazo entre receita e despesa e a discussão sobre medidas de ajuste fiscal [...] de modo a permitir a retomada do crescimento. A crise é mais profundo e requer um ajuste mais severo e estrutural. Medidas de aumento de receita para viabilizar um maior superávit primário [...] são insuficientes para superar os graves desafios enfrentados pelo país. [...] Ocorreu um severo descontrole dos gastos públicos a partir de 2009. Para além dos problemas de curto prazo, porém, existe um desequilíbrio estrutural. Desde 1991, a despesa pública tem crescido a uma taxa maior do que a renda nacional. Diversas normais legais que regulam as políticas públicas, da concessão de benefícios, como no caso da previdência, aos recursos alocados a áreas específicas, como saúde e educação, têm resultado no progressivo aumento dos gastos públicos maior que o crescimento da economia (Almeida et al., 2015, p. 1).

Almeida et al. (2015) e Pessoa (2016) apontam que, a partir de 2011, o crescimento da arrecadação tributária acima do crescimento do PIB cessou, com o nível de gasto público sendo mantido. No segundo semestre de 2014, o setor público passou a apresentar um déficit primário crescente. Tal comportamento teria advindo da forma como o governo reagiu à crise de 2009. Assim, houve uma "hipertrofia" dos bancos públicos na concessão de crédito a setores ineficientes escolhidos arbitrariamente, bem como uma política de desonerações que comprometeu a trajetória fiscal. Acrescenta-se a isso o fato de que os cortes da taxa básica de juros (Selic) teriam sido feitos de forma equivocada, desvalorizando a taxa de câmbio e, consequentemente, pressionando a inflação. Ainda que considerem o problema fiscal de caráter estrutural, as políticas da NME agravaram o problema, tornando ainda mais urgente a necessidade de um ajuste fiscal. Tais mudanças dentro do arranjo do tripé macroeconômico (metas de inflação, superávit primário e câmbio flutuante), juntamente com o represamento de preços administrados (combustíveis e energia elétrica), teriam causado distorções no sistema de preços, minando a confiança do empresariado e provocando a crise.

Desse modo, haveria três condicionantes para a crise. Primeiro, o descumprimento do superávit primário (um dos pilares do tripé macroeconômico) e a desvalorização da taxa de câmbio a partir de 2011 teriam agravado a situação, 
contribuindo para a crise. Cabe frisar que, nesse período, o Conselho de Política Monetária promoveu a queda da taxa básica de juros. Esta passou de 12,5\% em agosto de 2011 para 7,25\% em outubro de 2012 (Nassif, 2018; Carvalho, 2018). A elevação dos gastos públicos, sendo uma decisão de política econômica do governo Dilma Roussef e uma consequência da Constituição Federal de 1988, contribuiu para a desaceleração e posterior contração da economia. Segundo, a política industrial do governo Dilma, por meio do "Plano Brasil Maior", e o Programa de Sustentação do Investimento (PSI) tiveram um peso fiscal elevado com reduzido impacto no investimento (Nassif, 2018). Por fim, a adoção equivocada da NME foi crucial para o aprofundamento da crise (BOLLE, 2016).

Borges (2016) aponta que os erros que a abordagem convencional atribui a NME seriam exagerados. $O$ autor questiona até que ponto a recessão brasileira também não teria um forte componente de "azar". Para isso, mostra que, se comparados a países de renda média e exportadores líquidos de commodities, com o intuito de encontrar os efeitos líquidos da bad luck (fator exógeno) e da bad policy (fator endógeno) na recessão brasileira, o Brasil não teria um desempenho tão desfavorável em relação aos seus pares. Como resultado do comparativo de dados, Borges (2016) argumenta que cerca de $60 \%$ da recessão brasileira seria de um efeito exógeno, dada a deterioração dos termos de troca que teria igualmente afetado os países utilizados na sua comparação.

Bresser-Pereira (2017) destaca que o país teria entrado em crise por ter os seus cinco preços macroeconômicos desalinhados: a taxa de juros real estaria em um patamar elevado, a taxa de câmbio estaria sobreapreciada, a taxa de lucro teria sido espremida devido à perda de competitividade das empresas industriais, a inflação estaria elevada e os salários estariam elevados dada a apreciação cambial que apenas estimularia o consumo e não o investimento (Bresser-Pereira, 2017).

Para Oreiro (2017), a perda de sustentação do ritmo de crescimento da economia brasileira a partir do segundo trimestre de 2014 foi o resultado da queda da formação bruta de capital fixo. Mudanças abruptas dos investimentos são, em geral, decorrência de mudanças nas expectativas dos empresários a respeito da taxa de retorno do capital. Por isso, a taxa de retorno esperada vinha caindo ano após ano, bem como a própria taxa de retorno observada das empresas. Ao mesmo tempo, a redução da taxa Selic não compensou a queda da rentabilidade das empresas. Dessa forma, muitas empresas teriam sido prejudicadas pelo contexto macroeconômico, em que não conseguiam transferir o aumento dos custos operacionais aos seus preços de venda. A queda 
[...] das margens de lucro no setor industrial decorreu, por sua vez, do aumento do custo unitário do trabalho, gerado pelo aumento dos salários acima do crescimento da produtividade do trabalho; em conjunto com a sobrevalorização da taxa de câmbio, a qual impediu o repasse do aumento do custo unitário do trabalho para os preços dos produtos industriais devido à concorrência dos produtos importados (Oreiro, 2017, p. 79).

A queda acentuada dos investimentos ocorrida em 2014 foi o estopim da recessão, mas não explica o agravamento da intensidade do quadro recessivo observado em 2015 e a persistência desse quadro ao longo de 2016. Um fator que contribuiu para amplificar os efeitos do colapso do investimento foi o realinhamento súbito de preços relativos feito no início do segundo mandato de Dilma Rousseff. As tarifas de energia elétrica, que haviam sido reduzidas em 2013, foram reajustadas em cerca de 50\%, com o intuito de recuperar a rentabilidade das empresas de distribuição de energia negativamente afetadas pela política de controle de preços. A taxa nominal de câmbio também sofreu uma forte desvalorização nos três primeiros meses de 2015. Como resultado desse realinhamento de preços, a inflação passou de 6,41\%, no último trimestre de 2014, para $10,67 \%$ ao encerrar o ano de 2015. A aceleração da inflação resultou numa forte queda da renda real por trabalhador, e isso impactou fortemente o consumo das famílias (Oreiro, 2017).

Rezende (2016, 2017) afirma que a crise brasileira é uma crise do setor privado. A partir de 2007, com o crescimento das exportações de commodities e do mercado interno (Arestis et al., 2008; Rezende, 2016), o setor privado começa a reduzir as suas margens de lucro, com empresas iniciando novos projetos de investimento e as famílias consumindo mais. Com a concessão do grau de investimento pelas agências de crédito internacional ${ }^{2}$, há uma forte entrada de dólares no Brasil, o que apreciou a taxa de câmbio brasileira e aumentou o volume de importados. Esse processo aumentou a arrecadação tributária, beneficiando as contas do governo.

Rezende (2016) destaca que o upgrade do selo do Brasil junto às agências de crédito internacional de grau especulativo para grau de investimento reduziu a percepção de risco dos agentes privados, que responderam a isso adquirindo ativos de maior risco e alavancando seus balanços patrimoniais. A partir de 2014, as empresas financeiras e não-financeiras revertem o quadro de endividamento e passam a se desalavancar, causando a deterioração das contas do setor público. Essa

\footnotetext{
2 Em 2008, o Brasil obteve o título de grau de investimento pela agência Standard \& Poors, passando sua nota de crédito de BB+ (grau especulativo) para BBB- (grau de investimento).
} 
reversão do processo de endividamento privado provocaria em linhas keynesianas ${ }^{3}$ uma pressão no déficit público.

Com a crise do subprime nos Estados Unidos, o Brasil passou por uma recessão temporária em 2009, tendo as políticas contracíclicas um efeito direto nas empresas não financeiras, o que garantiu uma rápida recuperação da economia em 2010. A partir de 2011, o setor privado apresenta uma situação de fragilidade financeira, uma vez que não poderia aumentar seu endividamento indefinidamente (Godley, 1999a; Rezende, 2016). Nesse momento, o governo aplica uma política de aperto fiscal, comprometendo o investimento público (Rezende, 2016). Em 2012, o governo teria cometido um erro estratégico ao intervir em iniciativas econômicas muito pequenas, mal desenhadas, seguidas de decisões ad hoc, na tentativa de afinar a economia e gerar melhorias nas perspectivas econômicas do país a partir da NME (Rezende, 2016).

A partir do que foi discutido nesta seção, concluímos que existem diferentes interpretações da crise econômica nacional. A maioria dos trabalhos sugere problemas na condução da política econômica. Nas próximas seções, apresentaremos o modelo e o procedimento econométrico que testa a não causalidade de Granger para os setores da economia brasileira.

\section{Padrões de financiamento a partir da abordagem dos balanços setoriais}

Christ (1968) foi um dos primeiros trabalhos a empregar o modelo de três balanços. $O$ autor incorpora em seu modelo macroeconômico a consistência contábil entre os setores, apontando a diferença entre as restrições orçamentárias do setor privado e do setor público. O setor público apresentaria uma restrição orçamentária menos severa do que o setor privado, pois o setor público emite a sua própria moeda de curso forçado.

Ademais, os resultados encontrados por Cripps e Godley (1976) para a economia britânica geraram controvérsia ao analisar o efeito da política fiscal no

\footnotetext{
${ }^{3}$ A explicação para a pressão no resultado do setor público é encontrada na própria Teoria Geral de Keynes (1985). As receitas com tributos caem com a contenção do ímpeto dos empresários, o que aciona os estabilizadores automáticos do orçamento público, elevando os gastos. Os estabilizadores automáticos não se tratariam de gastos discricionários, mas sim de mecanismos constitucionais embutidos no orçamento do governo para contrabalançar a retração do setor privado. Ademais, recessões causariam queda na arrecadação tributária, de modo que o resultado do setor público tenha impactos negativos em termos de arrecadação e de despesa.
} 
balanço de pagamentos e o mérito das restrições às importações e depreciações cambiais como um meio de atingir o pleno emprego.

A partir de tal obra, eles efetuaram a desagregação dos componentes do balanço de pagamentos, da renda nacional, das contas públicas, de modo a investigar a estrutura de relações causais de modelos tradicionais em que há pleno emprego. Ainda que não tenham especificado o modelo de balanços nessa obra, ela se consagrou justamente por trazer à tona a consistência dos agregados macroeconômicos para contrastar com formulações mais tradicionais.

Ocampo et al. (2009) analisam as possíveis relações entre os saldos dos três balanços. Os autores avaliam empiricamente a variação nos fluxos dos três setores institucionais ao longo do tempo. Recomendações de políticas econômicas seguiram a interpretação de como os fluxos líquidos entre os setores se interrelacionam. O tópico de estudo bastante utilizado na literatura de macroeconomia tem sido identificar possíveis "gêmeos"; isto é, movimentos paralelos de déficit (ou superávit). Na abordagem convencional sobre países em desenvolvimento, há uma ênfase nos movimentos concomitantes entre déficit fiscal e déficit externo ${ }^{4}$. Segundo Ocampo et al. (2009), um "gêmeo alternativo" seria o déficit externo e déficit privado, verificado com maior frequência, implicando déficits em conta corrente que refletiriam os movimentos pró-cíclicos dos gastos do setor privado, os quais são financiados pelos empréstimos oriundos do resto do mundo. Essa configuração alternativa seria comum durante períodos de boom, quando há fácil acesso ao capital estrangeiro. Esses déficits seriam reduzidos (ou transformados em superávits) durante períodos de crise, resultado da redução do financiamento externo.

Diversas correntes propõem explicações para a dinâmica de fluxos em economias abertas. A correntes dos déficits gêmeos (DG) e os entusiastas da equivalência ricardiana (ER) são amplamente divulgados na literatura mainstream, colocando a questão fiscal como central para a resolução de problemas macroeconômicos. Por outro lado, as abordagens estruturalistas e das finanças externas instáveis abordam a dinâmica dos fluxos entre os setores. Nesses casos, a dinâmica de comércio internacional e as estruturas produtivas são os fatores que

\footnotetext{
${ }^{4}$ Quando a absorção doméstica é maior do que a produção doméstica, há déficit do setor externo, dada a necessidade de o país em questão ser um importador líquido. De acordo com a teoria monetarista, os déficits devem ser eliminados via ajuste fiscal, aumentando tributos e reduzindo gastos públicos. $\bigcirc$ ajuste teria como objetivo principal controlar a demanda doméstica por produtos importados, revertendo o sinal do saldo da balança comercial.
} 
regem a dinâmica dos fluxos entre o setor externo, setor privado e setor público (Ocampo et al., 2009).

A abordagem dos DG remonta à hipótese do economista do Fundo Monetário Internacional (FMI) Jacques Polak (1957) e está no centro dos pacotes de estabilização propostos pela instituição. A receita para a eliminação do déficit externo seria reduzir o déficit fiscal (VOLCKER, 1984). Dessa forma, a abordagem de Polak (1957) leva em conta uma abordagem monetarista do balanço de pagamentos. Assumindo as hipóteses de que todos os recursos estariam empregados e o nível de preços doméstico estaria ajustado pela paridade de poder de compra (PPC), uma elevação na demanda engendraria um maior déficit externo. A elevação da demanda e o consequente aumento do déficit externo levariam a uma desvalorização da taxa de câmbio, provocando um ajuste pelo lado da oferta no longo prazo.

A ER, oriunda de Barro (1974) e sendo uma abordagem novo-clássica, emerge da dinâmica dos modelos de poupança ótima, postulando que todos os recursos estariam plenamente empregados, e que as famílias suavizariam o consumo ao longo do tempo. Dessa forma, a abordagem de ER afirma que uma mudança da política fiscal será compensada por uma alteração inversamente proporcional do setor privado. A política fiscal anticíclica não poderia desempenhar um papel relevante, pois seria compensada por uma resposta contrária do setor privado. À medida que os déficits fiscais aumentam, o setor privado aumentaria sua poupança em antecipação aos impostos que ele terá que pagar no futuro para financiar a dívida adicional do setor público.

As abordagens de DG e ER seriam incompatíveis à medida que elas atribuem diferentes funções aos fluxos do setor privado e do setor externo. No modelo de DG, o balanço do setor privado é neutro e ele não responde a uma mudança dos fluxos fiscal ou externos. Nesse sentido, os déficits governamentais causariam o déficit externo (Abell, 1990). Isso ocorreria por dois canais principais (Nikiforos et al., 2015). O primeiro canal sugere (baseando-se na teoria do Loanable Funds) que o aumento dos déficits públicos estimula a demanda, provocando uma situação em que o investimento doméstico supera a poupança doméstica. Nesse caso, a oferta de fundos emprestáveis seria inferior à demanda por esses fundos, engendrando o aumento da taxa de juros com consequente influxo de capital para o país. Este último provocaria a valorização da taxa de câmbio e seu efeito negativo nas exportações líquidas (Nikiforos et al., 2015). O segundo canal decorreria de o aumento do gasto público implicar em uma demanda crescente e acima da 
capacidade instalada da economia, provocando, em última análise, o crescimento dos preços e a perda da competitividade internacional. Isso também contribuiria para uma deterioração da situação externa.

Já no modelo de ER, o saldo em conta corrente é neutro em relação à política fiscal, ao passo que os saldos do setor público e do setor privado se compensam. Nessa abordagem, residentes percebem (utilizando infinite-horizon optimization) que o aumento do déficit público acarretará maiores impostos no futuro, respondendo com uma redução do consumo no mesmo montante. Ocampo et al. (2009) referem que mesmo que as correlações projetadas pelas abordagens de DG e ER se verifiquem, suas assunções a respeito de causalidade macroeconômica não seriam válidas. A relação de causa poderia também ser interpretada no sentido contrário, do balanço do setor externo ou do balanço do setor público impactarem o setor privado, ou então o setor privado impactar o setor público. Economistas estruturalistas apontam que a restrição externa das economias faria com que o setor privado flutuasse de acordo com os ciclos internacionais (Prebisch, 1949; Ocampo et al., 2009).

Uma interpretação keynesiana, por exemplo, é contrária à da ER, uma vez que flutuações no setor privado é que ditam o ritmo da atividade, seja pelo animal spirit dos empresários, seja pela propensão a consumir. Políticas fiscais contracíclicas seriam necessárias justamente para compensar as flutuações no saldo do setor privado. Se o setor privado está contraído, gerando pouco consumo e pouco investimento, um déficit fiscal cumpriria um papel estabilizador, absorvendo o superávit do setor privado. Essa interpretação apenas reproduz a causalidade inversa em relação a ER.

A interpretação estruturalista aborda a questão de como países em desenvolvimento ajustariam a demanda efetiva para atender às restrições externas que são impostas pelas importações. Se o setor privado ou o setor público estão operando com déficits, isso irá gerar uma pressão no setor externo. Uma eventual desvalorização cambial decorrente do déficit externo geraria inflação, a qual reduziria a demanda do setor privado, que, ao contrair os seus gastos, retomaria uma posição superavitária. Pela lógica contábil, tal quadro geraria uma pressão no déficit público também. Essa interpretação também pode ser inversa: se ocorrem flutuações no setor externo e o setor privado é neutro, os déficits fiscais seriam determinados pelas mudanças no setor externo (Ocampo et al., 2009). Essa foi a abordagem adotada pela corrente das finanças externas instáveis, ressaltando que os capitais privados que fluem para países emergentes são instáveis (Ocampo et al., 
2009). Assim, os saldos domésticos se ajustariam à disponibilidade de financiamento externo, conforme a abordagem estruturalista. De fato, durante a década de 1970 houve uma abundância de empréstimos externos de economias avançadas para emergentes, havendo uma contrapartida no balanço fiscal. Logo, havia uma interação entre o saldo do setor público e o saldo do setor externo, mas com a causalidade invertida do que a apontada por Polak (1957). Para os países da América Latina, a contrapartida para a exuberância do setor externo ocorria no setor privado.

Feita essa breve discussão, partimos para a formalização do modelo. A primeira premissa do modelo é que um fluxo monetário líquido no setor governamental é igual ao fluxo monetário líquido do setor não governamental com o sinal invertido, como mostra a Equação 1, de forma que a soma de ambos os fluxos resulta em zero (Equação 2)

$$
\begin{gathered}
S G=-S N G \\
S G+S N G=0
\end{gathered}
$$

onde $S G$ é o saldo monetário do setor governamental e $S N G$ é o saldo monetário do setor não governamental, sendo válido para uma economia fechada. Godley (1999a) afirma que a visão tomada nessa abordagem é a de que desde que os estoques de ativos e passivos não tendam a crescer ou cair indefinidamente de acordo com os fluxos de renda, o PIB de um país deve seguir as interações entre os fluxos de renda entre os setores. Ademais, é possível incluir no modelo o setor externo, de forma que os fluxos possam entrar e sair da economia doméstica, bem como vazarem entre os setores institucionais domésticos. Chamaremos a partir de agora o setor governamental de setor público e desagregaremos o setor não governamental em demais setores a partir da derivação dos agregados macroeconômicos que compõem a renda nacional. De acordo com a ótica do dispêndio, tem-se

$$
Y=C+G+I+(X-M)
$$

onde $Y$ é a renda nacional; $C$ é o consumo agregado das famílias; $G$ é o gasto total do governo; I é investimento fixo; $X$ é o total de exportações de bens e serviços; e $M$ é o total de importações de bens e serviços. Podemos ainda expressar $C$ como resíduo da renda nacional $(Y)$, o que não foi poupado $(S)$ nem tributado $(T)$ 


$$
C=Y-S-T
$$

onde $S$ é a poupança agregada, e $T$ é o total de tributos recolhidos pelo governo. Substituindo $C$ da Equação 4 na Equação 3, tem-se

$$
0=(G-T)+(I-S)+(X-M)
$$

ou

$$
(S-I)=(G-T)+(X-M)
$$

de forma que $(S-I)$ é o superávit do setor privado; $(G-T)$ é o déficit do setor público; e $(X-M)$ é o superávit do setor externo ou saldo em conta corrente do balanço de pagamentos.

A intuição do modelo exposto em Godley (1999a), dado o rearranjo das variáveis, é que um déficit público e um superávit em conta corrente criam renda e ativos financeiros para o setor privado. Um superávit no setor público e um déficit em conta corrente retraem a renda e destroem os ativos financeiros do setor privado. Em outras palavras, o superávit do setor privado depende dos superávits das contas externas e do déficit público. Nikiforos et al. (2015) empregam essa relação para testar a causalidade entre os saldos dos setores para a Grécia. $\mathrm{Na}$ próxima seção, exploram-se os principais resultados do modelo supracitado.

\section{Metodologia e resultados}

Serão empregados os testes de não causalidade de Granger para o período de novembro de 2002 a junho de 2017. Conforme as equações 5 e 6 da seção anterior, será examinado se o saldo dos três grandes setores institucionais da economia brasileira (setor privado, setor público e setor externo) possuem relação de causa "no sentido Granger" durante o período supracitado. Dito isso, as hipóteses a serem testadas de acordo com os procedimentos são:

a) o resultado do setor privado causa no sentido Granger o resultado do setor público;

b) o resultado do setor público causa no sentido Granger o resultado do setor privado;

c) o resultado do setor externo causa no sentido Granger o resultado do setor público; 
d) o resultado do setor público causa no sentido Granger o resultado do setor externo;

e) o resultado do setor privado causa no sentido Granger o resultado do setor externo;

f) o resultado do setor externo causa no sentido Granger o resultado do setor privado.

O saldo do setor público ( $T-G$ e doravante $G G$ ) é denominado pelo resultado nominal do setor público consolidado medido em reais; o saldo do setor externo $(X-M$ e doravante $S X)$ é denominado pelo saldo em transações correntes do balanço de pagamentos medido em reais ${ }^{5}$; por último o saldo do setor privado $(S-I$ e doravante $S P)$ é o resíduo dos outros dois saldos, isto é, o saldo que satisfaça a identidade contábil entre os três setores. A periodicidade das séries é mensal, e os dados brutos foram extraídos das Séries Temporais do Banco Central do Brasil ${ }^{6}$. As verificações de cada período representam o saldo de cada setor dos últimos 12 meses acumulados. Cabe frisar a alteração no cômputo dos saldos setoriais com relação a seção anterior. Nesta seção e também nas demais (exceto quando for explicitamente mencionado), o saldo do setor público será o resultado da receita de impostos menos despesas do governo. De forma análoga, foi construído o saldo do setor privado (poupança menos investimento).

O período selecionado se refere ao início da série divulgada pelo Banco Central do Brasil (BCB, 2017) em novembro de 2002 até junho de 2017. O método de Toda e Yamamoto (1995) será empregado para testar a não causalidade de Granger entre as variáveis. Todas as estimações foram efetuadas pelo software Eviews, versão 7.0.

O teste de não causalidade de Granger pressupõe que as séries de tempo sejam estacionárias. Os testes tradicionais não são adequados na presença de variáveis integradas. Para verificar esse problema, pode-se utilizar o teste DickeyFuller aumentado (ADF), no qual a hipótese nula é que a série a ser testada possui raiz unitária. A vantagem da utilização do teste de Toda e Yamamoto (1995) é que

\footnotetext{
${ }^{5}$ Os dados das contas externas são divulgados em dólares pelo Banco Central do Brasil (BCB). Deduziu-se o saldo em reais através do saldo em transações correntes em proporção do PIB e do PIB nominal em reais.

${ }^{6}$ Para os dados do saldo do setor público, foi utilizada a série de código 17031. Para os dados das contas externas, foi empregada a série de código 22701.
} 
ele pode ser utilizado para séries cointegradas, não cointegradas e para séries com diferentes níveis de integração.

A ideia central do método de Toda e Yamamoto (1995) é a aplicação de um teste de Wald que verifica as restrições dos parâmetros de um modelo de VAR aumentado em níveis e estimado via mínimos quadrados ordinários. Os autores destacam que a aplicação do teste de Wald para verificar restrições dos parâmetros de um VAR $\left(k+e_{\text {max }}\right)$ aumentado em níveis segue uma distribuição assimptótica chi-quadrado $\left(\chi^{2}\right)$, independentemente do sistema ser cointegrado ou não. Para construir os sistemas, $k$ representa o número ótimo de defasagens e $e_{\text {max }}$ é a ordem máxima de integração das séries temporais. O teste de Wald é aplicado nos $k$ primeiros parâmetros, com a intenção de verificar a não causalidade de Granger, isto é, se há precedência temporal entre as séries. Os demais parâmetros defasados não são testados e servem somente para assegurar a presença de uma distribuição assimptótica chi-quadrado (MARQUETTI et al., 2009).

Portanto, o método de Toda e Yamamoto (1995) inclui três etapas. A primeira etapa consiste em encontrar o número de defasagens $(k)$ e a ordem máxima de integração do sistema $\left(e_{\max }\right)$, sendo o primeiro definido a partir do critério de informação de Schwartz (SIC), a fim de selecionar modelos mais parcimoniosos. Já a ordem de integração máxima do sistema seguirá um processo de integração de primeira ordem (processo mais comum em séries econômicas), isto é, $e_{\max }=1$, conforme será descrito nos resultados do teste de Dickey-Fuller aumentado (ADF).

A segunda etapa do procedimento diz respeito à estimação direta de um $\operatorname{VAR}\left(k+e_{\max }\right)$ em níveis para as três variáveis analisadas. As equações assumem a seguinte forma

$$
\begin{aligned}
& G G_{a}=c_{1}+\alpha_{1 j} \sum_{j=1}^{k} G G_{a j}+\delta_{1 j} \sum_{j=1}^{k} S X_{a j}+\alpha_{1 l} \sum_{l=k+1}^{e} G G_{a}+\delta_{1 l} \sum_{l=k+1}^{e} S X_{a}+\tau_{1 t} \\
& G G_{a}=c_{2}+\alpha_{2 j} \sum_{j=1}^{k} G G_{a j}+\delta_{2 j} \sum_{j=1}^{k} S P_{a j}+\alpha_{2 l} \sum_{l=k+1}^{e} G G_{a}+\delta_{2 l} \sum_{l=k+1}^{e} S P_{a}+\tau_{2 t} \\
& S X_{a}=c_{3}+\alpha_{3 j} \sum_{j=1}^{k} S X_{a j}+\delta_{3 j} \sum_{j=1}^{k} S P_{a j}+\alpha_{3 l} \sum_{l=k+1}^{e} S X_{a}+\delta_{3 l} \sum_{l=k+1}^{e} S P_{a}+\tau_{3 t}
\end{aligned}
$$




$$
\begin{aligned}
& S X_{a}=c_{4}+\alpha_{4 j} \sum_{j=1}^{k} S X_{a j}+\delta_{4 j} \sum_{j=1}^{k} G G_{a j}+\alpha_{4 l} \sum_{l=k+1}^{e} S X_{a}+\delta_{4 l} \sum_{l=k+1}^{e} G G_{a}+\tau_{4 t} \\
& S P_{a}=c_{5}+\alpha_{5 j} \sum_{j=1}^{k} S P_{a j}+\delta_{5 j} \sum_{j=1}^{k} G G_{a j}+\alpha_{5 l} \sum_{l=k+1}^{e} S P_{a}+\delta_{5 l} \sum_{l=k+1}^{e} G G_{a}+\tau_{5 t} \\
& S P_{a}=c_{6}+\alpha_{6 j} \sum_{j=1}^{k} S P_{a j}+\delta_{6 j} \sum_{j=1}^{k} S X_{a j}+\alpha_{6 l} \sum_{l=k+1}^{e} S P_{a}+\delta_{6 l} \sum_{l=k+1}^{e} S X_{a}+\tau_{6 t}
\end{aligned}
$$

onde $G G_{a}$ é o saldo do setor público, $S P_{a}$ é o saldo do setor privado e $S X_{a}$ é o saldo do setor externo. A terceira e última etapa envolve a realização dos testes de Wald nos $k$ primeiros parâmetros, com o intuito de averiguar a hipótese de não causalidade de Granger. Tem-se que

a) $S X$ Granger causa $G G$ se a hipótese $H_{0}: \delta_{1 j}=0$ for rejeitada;

b) $S P$ Granger causa $G G$ se a hipótese $H_{0}: \delta_{2 j}=0$ for rejeitada;

c) $S P$ Granger causa $S X$ se a hipótese $H_{0}: \delta_{3 j}=0$ for rejeitada;

d) $G G$ Granger causa $S X$ se a hipótese $H_{0}: \delta_{4 j}=0$ for rejeitada;

e) $G G$ Granger causa $S P$ se a hipótese $H_{0}: \delta_{5 j}=0$ for rejeitada;

f) $S X$ Granger causa $S P$ se a hipótese $H_{0}: \delta_{6 j}=0$ for rejeitada.

Portanto, por meio do procedimento de Toda e Yamamoto (1995), será possível verificar o suporte empírico das possíveis relações de causa atribuídas aos balanços setoriais. Assim sendo, o teste de não causalidade de Granger aponta a precedência temporal entre as variáveis observadas e também é útil para indicar uma previsão de comportamento futuro das variáveis. A seguir, nos Gráficos 1, 2 e 3 , estão expostos os comportamentos das três séries de tempo. 
Gráfico 1. Saldo do setor público (GG) em bilhões de reais (2002.11 - 2017.06)

\section{GG}

200

100

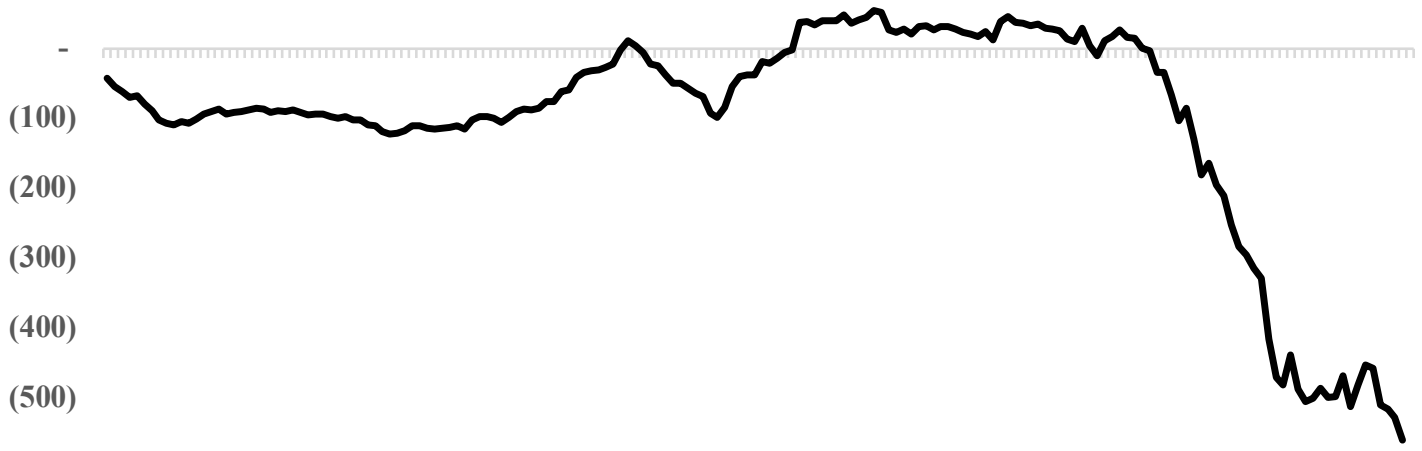

(600)

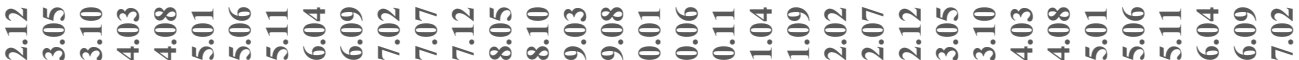

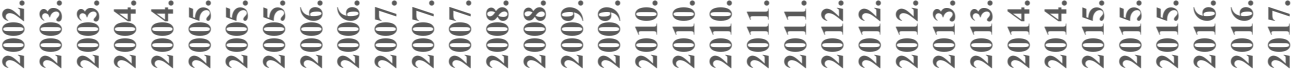

Fonte: Elaboração própria com base em BCB (2017).

Gráfico 2. Saldo do setor externo (SX) em bilhões de reais (2002.11 - 2017.06)

\section{SX}

200

100

(100)

(200)

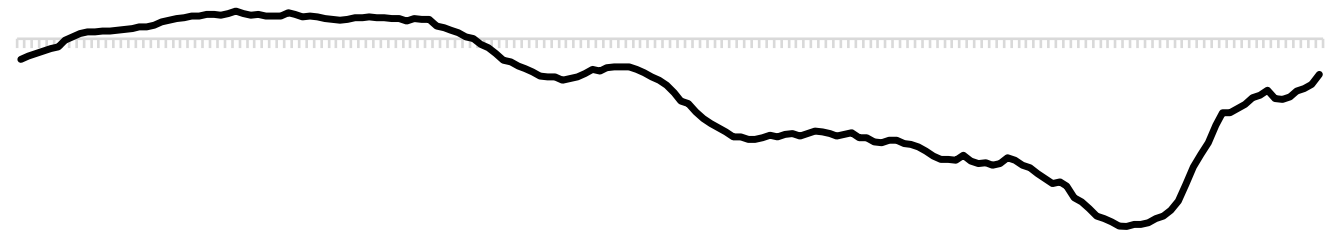

(300)

(400)

(500)

(600)

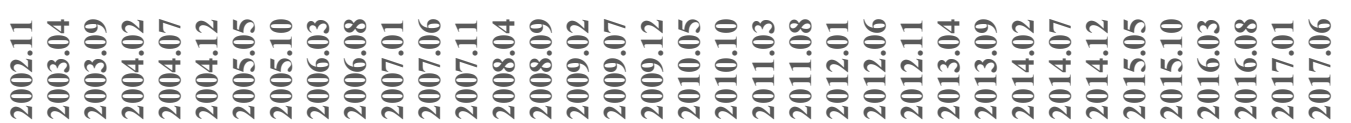

Fonte: Elaboração própria com base em BCB (2017). 
Gráfico 3. Saldo do setor privado (SP) em bilhões de reais (2002.11 - 2017.06)

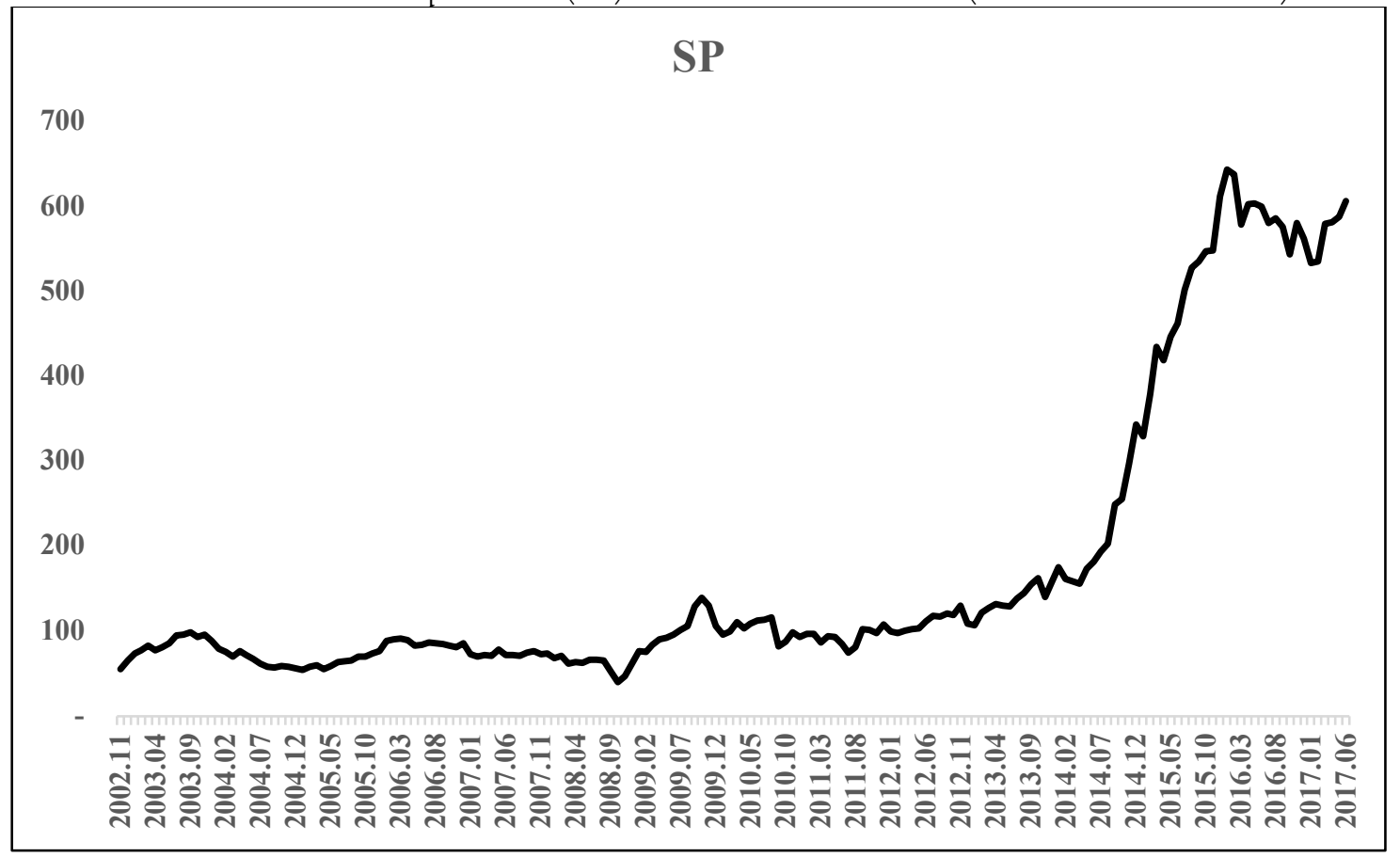

Fonte: Elaboração própria com base em BCB (2017).

Nos Gráficos acima constata-se um movimento oposto (correlação negativa) entre os saldos do setor público e do setor privado. Nota-se uma forte mudança de trajetória das séries a partir do segundo semestre de 2014. Ainda, efetuou-se a correlação parcial entre os setores, conforme a Tabela 1.

Tabela 1. Correlações parciais entre os 3 setores institucionais

\begin{tabular}{cccc}
\hline Período & $\begin{array}{c}\text { Setor Público } \mathbf{x} \\
\text { Setor Externo }\end{array}$ & $\begin{array}{c}\text { Setor Privado } \mathbf{x} \\
\text { Setor Externo }\end{array}$ & $\begin{array}{c}\text { Setor Público } \mathbf{x} \\
\text { Setor Privado }\end{array}$ \\
\hline $2003-2006$ & $-0,07^{*}$ & $0,92^{* * *}$ & $-0,45^{*}$ \\
$2007-2010$ & $0,62^{* * *}$ & $0,93^{* * *}$ & $0,30^{* * *}$ \\
$2011-2014$ & $-0,08^{* * *}$ & $0,33^{*}$ & $-0,97^{* * *}$ \\
$2015-2017.06$ & $-0,65^{*}$ & $0,91^{* * *}$ & $-0,91^{* * *}$ \\
$2002.11-2017.06$ & $0,01^{* * *}$ & $0,4^{* *}$ & $-0,84^{* * *}$ \\
\hline
\end{tabular}

Fonte: Elaboração própria com base em BCB (2017). Nota: Os indicadores marcados com *,** e * $^{* * *}$ são estatisticamente significantes a $10 \%, 5 \%$ e $1 \%$, respectivamente. 
A Tabela 1 mostra os resultados das correlações parciais entre os três balanços divididos em quatro subperíodos ${ }^{7}$ e a correlação de toda a série histórica. Extrai-se dos dados que o setor externo e o setor público possuem uma correlação bastante baixa se considerado todo intervalo de tempo da série. Contudo, para o intervalo entre 2007 e 2010, período de forte crescimento da economia brasileira, a trajetória dos dois setores teve uma correlação positiva de 0,62. Ademais, percebese que, para o período mais recente, entre janeiro de 2015 a junho de 2017, ambos os setores tiveram uma correlação de $-0,65$, justamente em um momento em que se ampliava o déficit em conta corrente e o déficit nominal do setor público. Ainda que correlação não indique relação de causa, tais informações chamam à atenção para como se dão as interações entre os setores da economia.

Os setores privado e externo não apresentam uma correlação substancial se considerada toda a série histórica. Porém, se analisados os subperíodos, entre 2003 e 2006 e entre 2007 e 2010, ambos os setores tiveram forte correlação positiva, com recortes acima de 0,9 , refletindo um momento de otimismo tanto no cenário externo quanto no setor privado, que aos poucos foi reduzindo seu saldo. $\bigcirc$ mesmo ocorreu no período recente entre janeiro de 2015 e junho de 2017, quando tanto o setor externo quanto o setor privado melhoravam os seus resultados.

O setor público e o setor privado possuem uma forte correlação inversa, o que remete à premissa mais básica dos modelos de três balanços: o saldo do setor público é o inverso do saldo do setor privado. Para toda a série temporal, ambos os setores possuem uma correlação de -0,84. Para os dois subperíodos mais recentes, entre 2011 e 2014 e janeiro de 2015 a junho de 2017, tal correlação inversa se intensifica, com os resultados encontrados de $-0,97$ e $-0,91$, respectivamente. As contas públicas brasileiras estiveram em sua melhor performance justamente nos períodos em que o setor privado despendia mais e poupava menos, ao passo que o inverso também é verdadeiro. Em suma, enquanto um setor melhora o seu saldo, o outro necessariamente está seguindo a trajetória inversa. A análise das correlações parciais dos setores instiga o seguinte questionamento: dado que os setores possuem uma correlação parcial estatisticamente significativa e forte, qual seria a relação de causa entre eles? Mais especificamente, chama à atenção a forte correlação negativa entre setor privado e setor público, o que coloca em contraste

\footnotetext{
7 Os dados são mensais para todas as análises. Onde não há indicação do mês, refere-se ao mês de janeiro ou ao mês de dezembro do ano indicado. Ainda que os subperíodos coincidam com o calendário de posse dos governos presidenciais, não se tem a intenção de fazer uma comparação entre eles.
} 
as relações de causa da abordagem keynesiana e da abordagem da ER de Barro (1974).

A Tabela 2 mostra os testes de raiz unitária para as variáveis em todas as especificações. Foi aplicado o teste Dickey-Fuller aumentado (ADF), a fim de verificar a ordem de integração das séries ${ }^{8}$.

Tabela 2. Teste de Raiz Unitária (ADF) para as variáveis da regressão

\begin{tabular}{|c|c|c|c|c|}
\hline VARIÁVEIS & MODALIDADE DO TESTE & DEFASAGENS & $\mathrm{ADF}$ & P-VALOR \\
\hline \multicolumn{5}{|l|}{ GG } \\
\hline & sem constante & 12 & 2,29 & 0,99 \\
\hline & com constante & 12 & 1,86 & 0,99 \\
\hline & com constante e tendência & 12 & 1,82 & 1,00 \\
\hline \multicolumn{5}{|c|}{ 然 } \\
\hline & sem constante & 3 & $-1,33$ & 0,17 \\
\hline & com constante & 3 & $-1,71$ & 0,42 \\
\hline & com constante e tendência & 3 & $-1,53$ & 0,81 \\
\hline \multicolumn{5}{|c|}{ 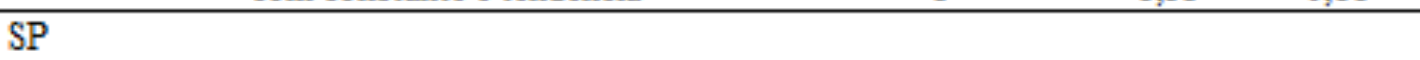 } \\
\hline & sem constante & 12 & 2,62 & 0,99 \\
\hline & com constante & 12 & 1,92 & 0,99 \\
\hline & com constante e tendência & 12 & 0,16 & 0,99 \\
\hline \multicolumn{5}{|l|}{$\mathrm{D}$ (GG) } \\
\hline & sem constante & 11 & $-2,99$ & 0,00 \\
\hline & com constante & 11 & $-3,25$ & 0,02 \\
\hline & com constante e tendência & 11 & $-4,22$ & 0,00 \\
\hline \multicolumn{5}{|l|}{$\mathrm{D}(\mathrm{SX})$} \\
\hline & sem constante & 2 & $-2,96$ & 0,14 \\
\hline & com constante & 2 & $-2,87$ & 0,00 \\
\hline & com constante e tendência & 2 & $-2,85$ & 0,05 \\
\hline \multicolumn{5}{|l|}{$\mathrm{D}$ (SP) } \\
\hline & sem constante & 11 & $-4,53$ & 0,00 \\
\hline & com constante & 11 & $-3,62$ & 0,00 \\
\hline & com constante e tendência & 11 & $-3,17$ & 0,00 \\
\hline
\end{tabular}

Fonte: Elaboração própria com base em BCB (2017). Nota: Cálculos extraídos do software Eviews 7.0 a partir do teste de Dickey-Fuller aumentado

número de defasagens para os testes $\mathrm{ADF}$ foi gerado automaticamente pelo software Eviews 7.0. Para as variáveis em nível, não houve nenhuma variável candidata à estacionariedade. A primeira diferença das séries também foi testada, não indicando presença de raiz unitária; com a exceção de $\mathrm{D}(\mathrm{SX})$, que, ao ser calculada sem constante ou tendência, dá indícios estatísticos de não possuir raiz

\footnotetext{
${ }^{8}$ As variáveis em primeira diferença estão representadas por $D(G G), D(S X)$ e $D(S P)$, onde $D(G G)$ é a primeira diferença do saldo do setor público, $\mathrm{D}(\mathrm{SX})$ é a primeira diferença do saldo do setor externo e D(SP) é a primeira diferença do saldo do setor privado.
} 
unitária pelo teste ADF. O método foi aplicado em um $\operatorname{VAR}(2)$ e $\operatorname{VAR}(3)$ para testar as causalidades de SX em GG, SP em GG, SX em SP e GG em SP. Para testar a causalidade de GG em SX e SP em SX foram testados modelos VAR(5) e $\operatorname{VAR}(6)^{9}$, de acordo com o número ótimo de defasagens $(k)^{10}$ e o número da ordem de integração máxima $\left(e_{\max }\right)$, que foi 1 para todas as variáveis, um resultado esperado dado que a maioria das séries econômicas segue uma ordem de integração I(1). Os resultados das especificações testadas para o Teste de Wald ${ }^{11}$ são apresentados na Tabela 3. ${ }^{12}$

Tabela 3. Relações de causalidade de Granger para o Brasil: 2002-2017

\begin{tabular}{ccc}
\hline S e tor P úblico & S e tor P úblico & S e tor P riva do \\
$\mathrm{x}$ & $\mathrm{x}$ & $\mathrm{X}$ \\
S e tor P riva do & S e tor Exte rno & S e tor Exte rno \\
\hline GG $\longleftarrow$ S P & GG S S & S P $\longleftrightarrow$ S X
\end{tabular}

Fonte: Elaboração própria com base nas estimações econométricas. Nota: As variáveis GG, SP e SX representam, respectivamente, os saldos dos setores público, privado e externo.

Da análise da Tabela 3, observa-se que o saldo do setor privado causa no sentido de Granger o saldo do setor público, e o saldo do setor externo causa o saldo do setor público. Tais resultados mostram que tanto o setor privado quanto o setor externo influenciaram a trajetória das contas públicas.

\footnotetext{
${ }^{9}$ Foram realizados os testes para verificar existência de autocorrelação dos resíduos (Lagranger Multiplier Test) e heteroscedasticidade (Teste de White). Nenhuma das especificações indicou presença de autocorrelação. Todas as especificações rejeitaram a hipótese de homoscedasticidade. Também foi procedido o teste de normalidade dos resíduos e não se verificou nenhum problema quanto a isso em nenhuma especificação. Efetuou-se a correção da matriz heteroscedasticidade através do método de Newey-West, que é uma extensão da correção de White. O método de Newey-West também efetua a correção do problema de autocorrelação, caso seja necessário. Os erros-padrão gerados são HAC (Heteroskedasticity-Autocorrelation Consistent). Feita a correção é possível fazer a estimação dos modelos VAR através de mínimos quadrados ordinários.

${ }^{10}$ Para as variáveis $G G$ e $S P$, o número de defasagens ótimas $(k)$ foi 1 , de acordo com critério SIC. Pelo mesmo critério, verificou-se que $\circ k$ de $S X$ foi 4 . Os modelos VAR são calculados com $k+e_{\text {max }}$ defasagens e com $k+e_{\max }+1$ defasagens, com intuito de testar se há uma mudança significativa do resultado no caso de se adicionar uma defasagem ao modelo. Logo, todas as seis especificações descritas nas Equações de 9 a 15 terão modelos VAR rodados com diferentes números de defasagens para efetuar tal controle.

${ }^{11}$ Pelos testes de não causalidade de Granger comum (o teste rodado pelo Eviews 7.0), chegamos ao resultado de que, em quaisquer especificações das 12 possíveis, todas as variáveis teriam precedência temporal em relação às demais, redundando em uma conclusão de que "tudo causa tudo".

${ }^{12}$ Foram considerados válidos os testes de hipótese que apresentaram um p-valor abaixo de 0,05.
} 
Tal resultado vai ao encontro da teoria keynesiana, uma vez que, com a contração dos investimentos do setor privado, haveria uma queda nas receitas tributárias e também o acionamento de estabilizadores automáticos do orçamento governamental, causando um déficit público (KEYNES, 1985). Embora os dados da Tabela 1 indiquem uma correlação parcial fraca para todo o período de 2002 a 2017 (possivelmente decorrente de quebras estruturais nas séries temporais ${ }^{13}$ ), para os subperíodos de 2007-2010 e 2015-2017, o saldo do setor externo apresentou uma forte correlação com o saldo das contas públicas. Logo, os resultados da Tabela 1 juntamente com as informações da Tabela 3 sugerem uma relação causal inversa da suposta na teoria dos déficits gêmeos.

As estimações do presente estudo contestam as interpretações liberais sobre a crise. Os resultados negativos do setor público são o reflexo da crise econômica, não vice-versa. Os movimentos dos saldos do setor público responderam aos desequilíbrios dos setores privado e externo. Esse resultado está em linha com as interpretações de Godley (1999a), Borges (2016) e Rezende (2017).

No Gráfico $2,{ }^{14}$ o saldo do setor público é dado com o sinal positivo para mostrar que o superávit do setor privado é igual ao déficit do setor público adicionado ao saldo em conta corrente. Para facilitar a visualização, os saldos plotados estão medidos em proporção ao PIB do ano corrente.

Entre 2004 e 2008, com os preços de commodities em trajetória ascendente, o saldo do setor público se manteve relativamente estável, com exceção de 2009, quando das políticas anticíclicas executadas pelo governo em combate à crise financeira global. Mesmo com a queda do volume de exportações, fruto da forte queda dos preços internacionais de commodities em 2014, a recessão brasileira impactou a demanda doméstica a ponto de as importações terem uma queda ainda maior do que a queda das exportações. Soma-se a isso uma depreciação cambial a partir do final de 2014, que acabou tendo um impacto positivo no saldo externo brasileiro. O setor privado, dada sua alta percepção de risco, retrai seus

\footnotetext{
${ }^{13}$ Cabe referir que o procedimento de Toda e Yamamoto (1995) consegue captar eficientemente a relação entre variáveis mesmo na presença de quebras estruturais.

${ }^{14}$ Para o balanço do setor público, ilustrado com sinal contrário, i.e., ilustrando um déficit, usamos o saldo nominal do setor público consolidado acumulado em 12 meses e medido em proporção do PIB. Para o balanço do setor externo, usamos o saldo em conta corrente acumulado nos últimos 12 meses medido em proporção do PIB, utilizando a nova metodologia de cálculo do balanço de pagamento convencionada pelo FMI (BPM6). O saldo do setor privado é um resíduo de ambas as contas. Os dados extraídos são mensais. Foram plotados os dados desde novembro de 2002, quando do início da nova metodologia de cálculo para as finanças públicas, até a última data em que todas estatísticas estavam disponíveis durante a confecção do presente trabalho.
} 
investimentos e aumenta a sua poupança, tendo uma melhora substancial do seu saldo principalmente a partir de 2014, quando a retração econômica tem início no Brasil. As quedas do PIB em 2015 e em 2016 impactaram as importações, engendrando o ajuste do setor externo durante esse período. $O$ déficit externo, que se encontrava em mais de $4,5 \%$ do $\mathrm{PIB}$, dirigiu-se para um patamar de pouco mais de $0,5 \%$ do PIB na metade de 2017.

Gráfico 2. Saldo dos três maiores balanços financeiros no Brasil acumulado em 12 meses (\% PIB)

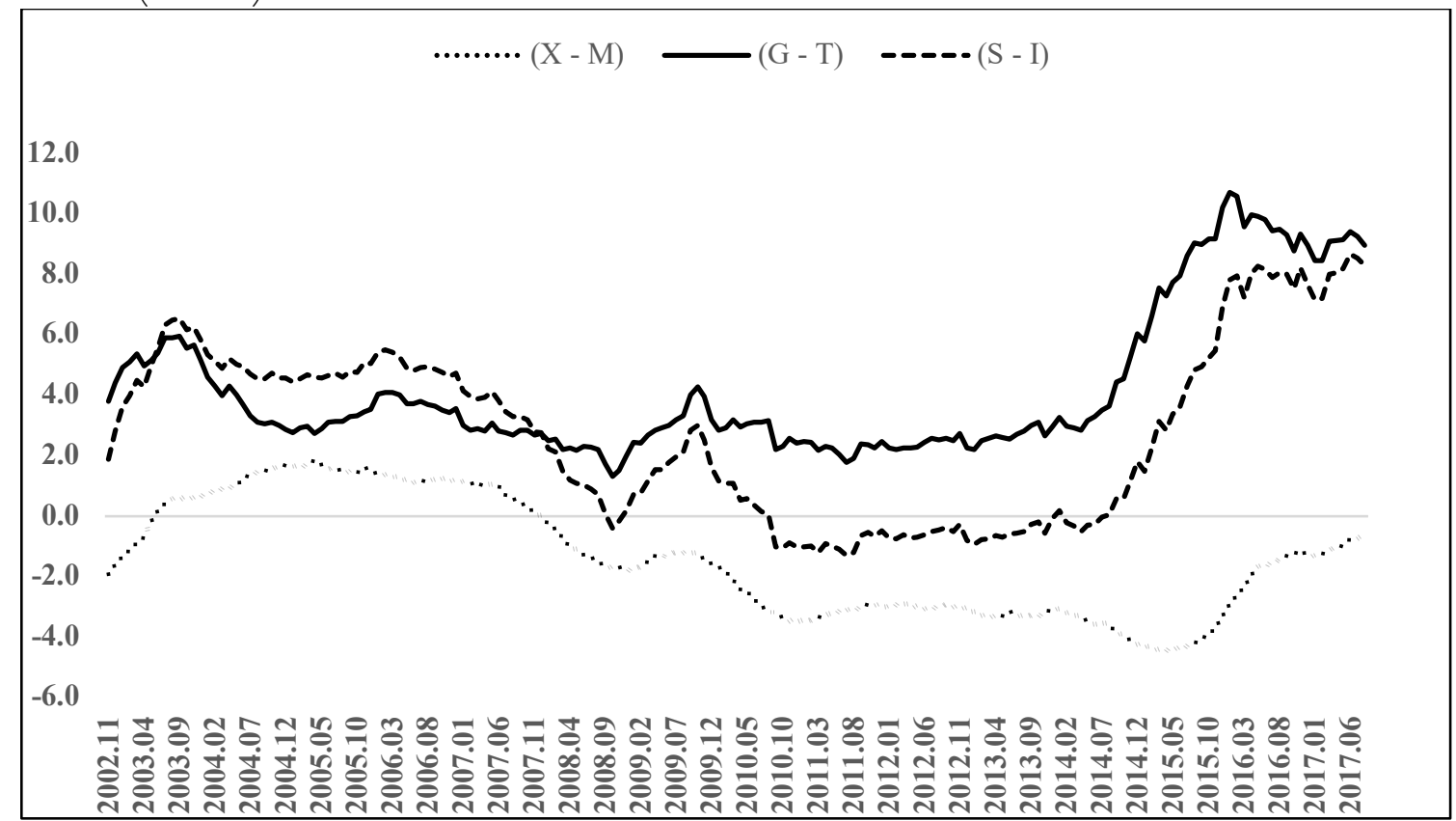

Fonte: Elaboração própria com base em BCB (2017).

Nota-se que, a partir de 2014, houve queda nos investimentos, além da queda dos preços internacionais de commodities, que impactaram o saldo das exportações líquidas. Tal processo engendrou uma pressão negativa sobre as contas públicas. Ademais, o processo de aumento das taxas de juros, que ocorreu do início de 2013 até metade de 2015, impactou o volume de pagamento de juros e amortizações por parte do setor público.

Portanto, os resultados do procedimento de Toda e Yamamoto (1995) sugere que a mudança do cenário externo e o comportamento do setor privado condicionaram a piora do saldo do setor público. Esse processo teve início durante a crise financeira global, tendo o seu desencadeamento com maior intensidade em meados de 2014. Isso dá respaldo para as abordagens heterodoxas de Keynes (1936 [1985]), Godley (1999a), Borges (2016) e Rezende (2017). Um longo ciclo de commodities puxou o crescimento brasileiro até 2014, bem como o setor privado ampliou sistematicamente seu consumo e investimento enquanto ainda havia um 
cenário externo favorável, resultando em sucessivos anos de aumentos de fragilidades, com seus lucros crescendo em uma velocidade muito menor do que suas dívidas. Com o fim de um ciclo que vinha de fora do Brasil, tal quadro se reverteu e engendrou uma recessão de dois anos.

\section{Considerações Finais}

objetivo do presente artigo foi averiguar, por meio da aplicação do método de Toda e Yamamoto (1995), quais são as causas principais da crise brasileira. Ainda que o país já tenha saído de estado de recessão técnica ao final de 2017 e tenha a perspectiva de retomar um ritmo modesto de crescimento para os próximos anos ${ }^{15}$, o debate acerca das causas da crise econômica ainda merece destaque. Economistas liberais, em geral, atribuem a crise à adoção da Nova Matriz Econômica (NME). Por parte desse ponto de vista, o Brasil teria passado por período de progresso até 2009, quando preservava à risca a estrutura do tripé macroeconômico (metas de inflação, superávit primário e câmbio flutuante), mas as políticas intervencionistas para combate à crise mundial teriam causado uma série de distorções microeconômicas e a deterioração do quadro fiscal.

As interpretações alternativas apontam que os indicadores fiscais brasileiros são apenas uma consequência da crise (Borges, 2016; Rezende, 2017). A crise brasileira estaria centrada no setor privado, baseando-se no argumento de que o otimismo oriundo do cenário externo permitiu que as empresas brasileiras dessem andamento a projetos de investimento, engendrando um processo de alavancagem. Quando o quadro de otimismo é revertido, o setor privado começa a contrair seus investimentos, desencadeando a queda na atividade econômica e, consequentemente, uma pressão negativa nas contas públicas.

Dados os diferentes pontos de vista acerca da crise brasileira, buscou-se compreender, por meio da aplicação do modelo de balanços setoriais (Cripps e Godley, 1976), como interagem setor privado, setor público, e setor externo. A ideia central do modelo consiste no fato de que a soma dos fluxos líquidos dos setores de uma economia é igual a zero, de modo que todo fluxo que sai de um lugar vai para outro. Portanto, para existir um setor operando em superávit, deve necessariamente existir algum outro operando em déficit (Godley, 1999a).

\footnotetext{
${ }^{15}$ Conforme o Boletim Focus, do Banco Central do Brasil, verificado na data da elaboração do artigo, para 2018 e 2019, a previsão é de que o país tenha um crescimento econômico de 2,87\% e de 3,0\% ao ano, respectivamente. Se concretizadas as previsões, o país chegará em 2020 ainda com um nível de atividade abaixo do nível de 2014.
} 
A partir do procedimento econométrico de Toda e Yamamoto (1995), testaram-se as possíveis relações de causa entre os setores institucionais. Identificou-se que existem evidências estatísticas para dar suporte a duas abordagens no caso brasileiro: primeiro, a abordagem keynesiana, em que o setor privado possui influência no setor público (Keynes, 1985); segundo, a abordagem estruturalista, em que o setor externo impacta o setor público (Prebisch, 1949; Ocampo et al., 2009). Os testes econométricos efetuados através do procedimento de Toda e Yamamoto (1995) dão suporte para o argumento de que foi a reversão do cenário internacional e do forte endividamento do setor privado brasileiro que pressionaram o déficit do setor público (Keynes, 1985; Ocampo et al., 2009; Rezende, 2017). Assim, os resultados indicam que a crise decorreu principalmente do excessivo endividamento privado e de choques externos negativos, não sendo proveniente de desequilíbrios do setor público. Os possíveis desajustes provocados pela política econômica do Governo Dilma Roussef parecem ter desempenhado um papel secundário para a explicação da crise.

Portanto, de acordo com os resultados encontrados no modelo, entende-se que uma política de ajuste fiscal não seria adequada para combater a crise brasileira, uma vez que isso se refletiria em uma ação sobre um sintoma da crise, e não sobre sua causa. Se o setor privado está em uma posição frágil e contraída, caberiam políticas que garantissem a sua solvência e estimulassem uma retomada dos projetos de investimento. Ainda, pelo lado do setor externo, políticas estruturais que evitassem uma dependência dos ciclos externos e do agravamento do déficit em conta corrente em períodos de expansão também seriam importantes.

\section{Referências}

Abell, J. D. (1990). Twin deficits during the 1980s: An empirical investigation. Journal of macroeconomics, 12(1), 81-96.

Almeida, M., Lisboa, M. B., \& Pessoa, S. (2015). O ajuste inevitável. Folha de São Paulo. Disponivel em: <http://www1.folha.uol.com.br/fsp/ ilustrissima/226576-ajuste-inevitavel.shtml

Arestis, P., de Paula, L. F., \& Ferrari, F. (2007). Assessing the economic policies of President Lula da Silva in Brazil: has fear defeated hope? In: P. Arestis \& M. Sawyer (Eds.) Political economy of Latin America: recent economic performance. Basingstoke: Palgrave Macmillan. 
BCB - Banco Central Do Brasil. (2017). Séries temporais. Disponível em: $<$ http://www4.bcb.gov.br/pec/series/port/aviso.asp $>$. Acesso em 10 de outubro de 2017

Barro, R. J. (1974). Are government bonds net wealth? Journal of political economy, 82(6), 1095-1117.

Bolle, M. B. (2016). Como matar a borboleta-azul: Uma crônica da era Dilma. Rio de Janeiro: Intrínseca.

Borges, B. (2016). Bad Luck or Bad Policy: uma investigação das causas do baixo crescimento da economia brasileira nos últimos anos. In: R. Bonelli \& $\mathrm{F}$. Veloso (Orgs.), A Crise de Crescimento no Brasil. Elsevier/FGV-Ibre.

Bresser-Pereira, L. C. (2017). Como sair do regime liberal de política econômica e da quase-estagnação desde 1990. Estudos Avançados, 31(89), 7-22. doi: 10.1590/s0103-40142017.31890002

Carvalho, L.B. (2018). Valsa brasileira: do boom ao caos econômico. São Paulo: Todavia.

Christ, C. F. (1968). A simple macroeconomic model with a government budget restraint. The Journal of Political Economy, 76(1), 53-67.

Cripps, F., \& Godley, W. (1976). A formal analysis of the Cambridge economic policy group model. Economica, New Series, 43(172), 335-348. doi: $10.2307 / 2553270$

Godley, W. (1999a). Seven unsustainable processes. New York: Levy Economic Institute of Bard College, Annandale-on-Hudson.

Keynes, J. M. (1936 [1985]). A Teoria Geral do Emprego, do Juro e da Moeda. São Paulo: Nova Cultural.

Marquetti, A., Koshiyama, D., \& Alencastro, D. (2009). O aumento da lucratividade expande a acumulação de capital? Uma análise de causalidade de Granger para países da OCDE. Revista de Economia Contemporânea, 13(3), 367390. doi: 10.1590/S1415-98482009000300001

Nassif, A. (2018). A valsa não totalmente afinada de Laura Carvalho: um ensaioresenha crítico de Valsa brasileira: do boom ao caos econômico. Cadernos do Desenvolvimento, 13(23), 11-35. 
Nikiforos, M., Carvalho, L., \& Schoder, C. (2015). "Twin deficits" in Greece: in search of causality. Journal of Post Keynesian Economics, 38(2), 302-330. doi: 10.1080/01603477.2015.1065675

Ocampo, A. C., Rada, C., \& Taylor, L. (2009). Growth and policy in developing countries: A structuralist approach. Columbia University Press.

Ocampo, J. (2009). Patterns of Net Borrowing in Open Developing Economies. In J. A. Ocampo, C. Rada, \& L. Taylor (Orgs.), Growth and policy in developing countries: a structuralist approach (pp. 75-83). New York: Columbia University Press.

Oreiro, J. L. (2017). A grande recessão brasileira: diagnóstico e uma agenda de política econômica. Estudos Avançados, 31(89), 75-88. doi: 10.1590/s010340142017.31890009

Pessoa, S. (2016). Crise fiscal estrutural deve resultar em alta inflação no médio prazo. Revista Conjuntura Econômica, 70(10), 10-11.

Polak, J. J. (1957). Monetary analysis of income formation and payments problems. International Monetary Fund Staff Papers, 6(1), 1-50. doi: 10.2307/3866128

Prebisch, R. (1949). O desenvolvimento econômico da América Latina e seus principais problemas. Revista Brasileira de Economia, 3(3), 47-111.

Rezende, F. (2016). Financial fragility, instability and the Brazilian crisis: a KeynesMinsky-Godley approach. Minds (Multidisciplinary Institute for Development and Strategies): Discussion paper, 1.

Rezende, F. (2017). Desalavancagem do setor privado. Valor Econômico. Disponível em: <http://www.valor.com.br/opiniao/5038378/ desalavancagem-do-setor-privado>

Toda, H., \& Yamamoto, T. (1995). Statistical inference in vector autoregressions with possibly integrated processes. Journal of Econometrics, 66(1-2), 225250. doi: 10.1016/0304-4076(94)01616-8

Volcker, P.A. (1984). Facing up to the twin deficits. Challenge, 27(1), 4-9. doi: 10.1080/05775132.1984.11470902 